\title{
Robust Active Suspension Control for Vibration Reduction of Passenger's Body
}

\author{
Takuma Suzuki and Masaki Takahashi \\ Keio University \\ Japan
}

\section{Introduction}

An automotive performance has improved from the demand of ride comfort and driving stability. Many research have proposed various control system design methods for active and semi-active suspension systems. These studies evaluated the amount of reduced vibration in the vehicle body, i.e., the vertical acceleration in the center-of-gravity (CoG) of the vehicle's body (Ikeda et al., 1999; Kosemura et al., 2008; Itagaki et al., 2008). However, any passengers always do not sit in the CoG of the vehicle body. In the seated position that is not the CoG of the vehicle body, vertical acceleration is caused by vertical, roll and pitch motion of the vehicle. In nearly the resonance frequency of the seated human, the passenger's vibration becomes larger than the seated position's vibration of the vehicle body due to the seated human dynamics.

The seated human dynamics and human sensibility of vibration are cleared by many researchers. So far some human dynamics model has been proposed (Tamaoki et al., 1996, 1998, 2002; Koizumi et al., 2000). Moreover, some of them are standardized in ISO (ISO-26311, 1997; ISO-5982, 2001). At the research as for automotive comfort with the passengervehicle system, M.Oya et al. proposed the suspension control method considering the passenger seated position in the half vehicle model (Oya et al., 2008). G.J. Stein et al. evaluated passenger's head acceleration at some vehicle velocities and some road profiles (Guglielmino et al., 2008). There are few active suspension control design methods which are positively based on a passenger's dynamics and the seating position. These methods can be expected to improve the control performance.

In this paper, new active suspension control method is developed to reduce the passenger's vibration. Firstly, a vehicle and passenger model including those dynamics at seated position is constructed. Next, a generalized plant that uses the vertical acceleration of the passenger's head as one of the controlled output is constructed to design the linear $H_{\infty}$ controller. In this paper, this proposed method defines as "Passenger Control". "Passenger Control" means passenger's vibration control. Moreover, in an active suspension control, it is very important to reduce the vibration at the condition of the limited actuating force. Then, we design two methods which are "Vehicle CoG Control", and "Seat Position Control", and compare the proposed method with two methods. "Vehicle CoG Control" means vibration control of vehicle. "Seat Position Control" means vibration control of seat position. Finally, several simulations are carried out by using a full vehicle model which has active suspension system. From the result, it was confirmed that in nearly the resonance 
frequency of a passenger's head in the vertical direction, "Passenger Control" is effective in reducing a passenger's vibration better than "Vehicle CoG Control" and "Seat Position Control". The numerical simulation results show that the proposed method has the highest control performance which is vibration reduction of the passenger's head per generated force by the active suspension. Moreover, the results show that the proposed method has robustness for the difference in passenger's vibration characteristic.

\section{Modeling}

\subsection{Modeling of the vehicle}

Figure 1 shows a full vehicle model which is equipped with an active suspension between each wheel and the vehicle body. The weight of the vehicle body is supported by the spring. We assume that a vehicle model is a generic sedan car as shown in Table 1 . The equations of motion which are, bounce, roll, pitch and each unsprung motion are as follows:

$$
\begin{gathered}
M_{b} \ddot{z}_{c g}=\sum_{i=1}^{4} f_{s i}, \\
I_{r} \ddot{\phi}=\frac{T_{f}}{2}\left(f_{s 1}-f_{s 2}\right)+\frac{T_{r}}{2}\left(f_{s 3}-f_{s 4}\right)+M_{b} g H_{r} \phi, \\
I_{p} \ddot{\theta}=-L_{f}\left(f_{s 1}+f_{s 2}\right)+L_{r}\left(f_{s 3}+f_{s 4}\right)+M_{b} g H_{p} \theta, \\
M_{t i} \ddot{z}_{u i}=-F_{d i}+K_{t} z_{t i}(i=1, \cdots, 4) .
\end{gathered}
$$

where $H_{r}$ is the distance from a roll center to the CoG of the vehicle body, and $H_{p}$ is the distance from a pitch center to the CoG of the vehicle body. These parameters are constant. The spring coefficients of each wheel are different from each other, and were set to $K_{1,2}=K_{f}$, $K_{3,4}=K_{\mathrm{r}}, z_{s i}$ means a suspension stroke of each wheel, $z_{t i}$ means deformation of the each tire.

$$
\begin{aligned}
& z_{s 1}=z_{c g}+T_{f} / 2 \phi-L_{f} \theta-z_{u 1} \\
& z_{s 2}=z_{c g}-T_{f} / 2 \phi-L_{f} \theta-z_{u 2} \\
& z_{s 3}=z_{c g}+T_{r} / 2 \phi+L_{r} \theta-z_{u 3} \\
& z_{s 4}=z_{c g}-T_{r} / 2 \phi+L_{r} \theta-z_{u 4} \\
& z_{t i}=z_{r i}-z_{u i}(i=1, \cdots, 4)
\end{aligned}
$$

The spring and damping forces which act between the wheels and the vehicle body, are given by the following equation.

$$
F_{d i}=-K_{i} z_{s i}-C_{i}(t) \dot{z}_{s i} \quad(i=1, \cdots, 4)
$$

\subsection{Modeling of the passenger}

Various models of a seated human have been proposed so far. In this paper, the passenger's motion is expressed to the seated human model shown in Fig. 2. Therefore, it is easy to understand the passenger's motion. To the seated position, Ps, the body part has three 

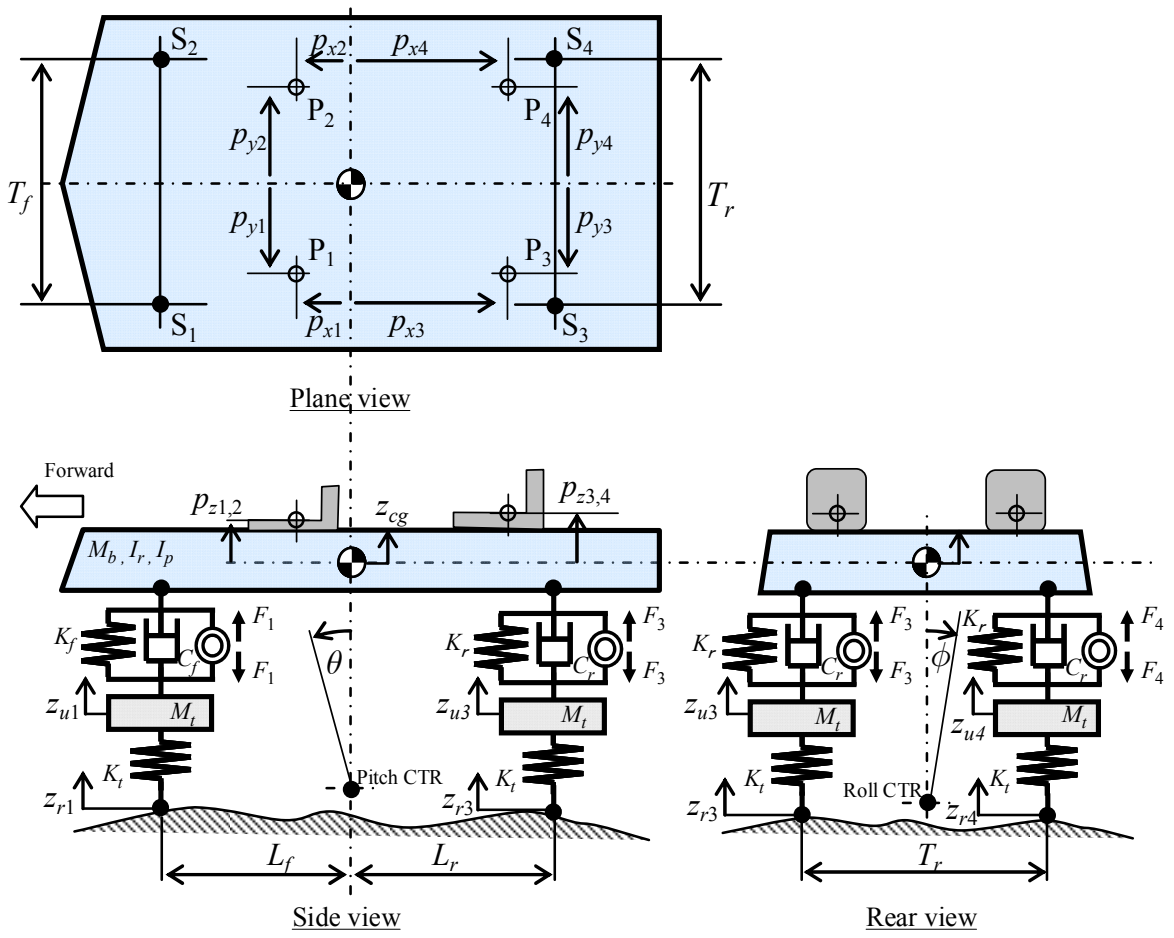

Fig. 1. Full vehicle model

\begin{tabular}{|c|cc||c|cc|}
\hline Symbol & \multicolumn{2}{|c|}{ Value } & Symbol & \multicolumn{2}{c|}{ Value } \\
\hline \hline$M_{b}$ & 1900 & $\mathrm{~kg}$ & $T_{f}$ & 1.53 & $\mathrm{~m}$ \\
\hline$M_{t}$ & 50 & $\mathrm{~kg}$ & $T_{r}$ & 1.50 & $\mathrm{~m}$ \\
\hline$I_{r}$ & 600 & $\mathrm{kgm}^{2}$ & $H_{r}$ & 0.45 & $\mathrm{~m}$ \\
\hline$I_{p}$ & 3000 & $\mathrm{kgm}^{2}$ & $H_{p}$ & 0.53 & $\mathrm{~m}$ \\
\hline$K_{f}$ & $33 \times 10^{3}$ & $\mathrm{~N} / \mathrm{m}$ & $p_{x 1,2}$ & 0.04 & $\mathrm{~m}$ \\
\hline$K_{r}$ & $31 \times 10^{3}$ & $\mathrm{~N} / \mathrm{m}$ & $p_{y 1}$ & 0.4 & $\mathrm{~m}$ \\
\hline$K_{t}$ & $260 \times 10^{3}$ & $\mathrm{~N} / \mathrm{m}$ & $p_{y 2}$ & -0.4 & $\mathrm{~m}$ \\
\hline$L_{f}$ & 1.34 & $\mathrm{~m}$ & $p_{z 1,2}$ & -0.045 & $\mathrm{~m}$ \\
\hline$L_{r}$ & 1.46 & $\mathrm{~m}$ & & & \\
\hline
\end{tabular}

Table 1. Specification of vehicle mode

degree of freedom (DOF) which is longitudinal, lateral, and vertical motions. The head has 3 DOF. First, the head moves up and down to the body parts. Second, the head rotates around the point, $\mathrm{Pp}$, at the pitch direction. Third, the head rotates around the point, Pr, at the roll direction. Thus the passenger model has a total of 6 DOF. Between the each part, it has a spring and a damper. The equation of motion of the passenger model is as follows. 


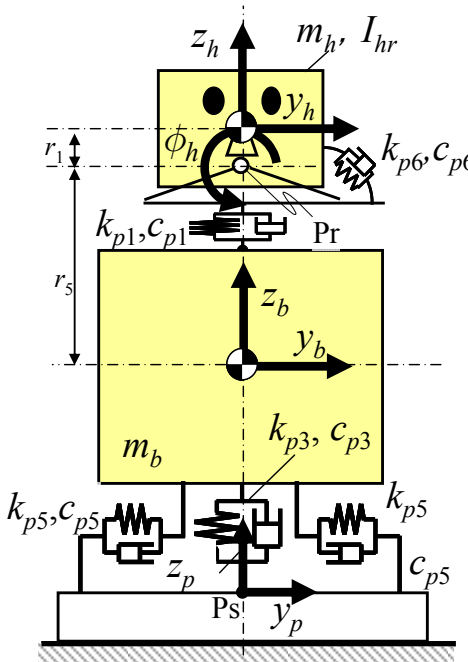

Front view

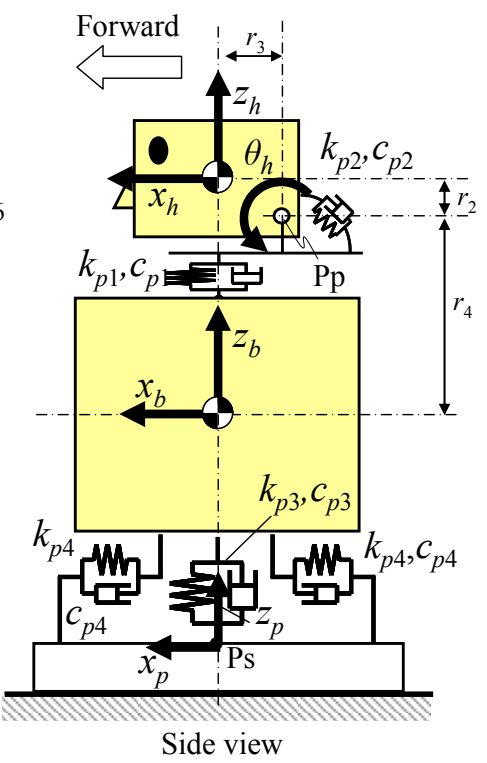

Fig. 2. Passenger model

\begin{tabular}{|c|c|c|c|}
\hline$i$ & $k_{p i}$ & $\begin{array}{c}c_{p i} \\
{[\mathrm{~N} / \mathrm{m} / \mathrm{s}]}\end{array}$ & $\begin{array}{c}r_{p i} \\
{[\mathrm{~m}]}\end{array}$ \\
\hline \hline 1 & 40000 & 2000 & 0.1 \\
\hline 2 & $15^{*}$ & $0.9^{* *}$ & 0.1 \\
\hline 3 & 96000 & 1120 & 0.05 \\
\hline 4 & 22500 & 600 & 0.2 \\
\hline 5 & 2000 & 400 & 0.3 \\
\hline 6 & $20^{*}$ & $1.2^{* *}$ & 0.3 \\
\hline
\end{tabular}

Table 2. Specification of passenger model $\left({ }^{*}: \mathrm{Nm} / \mathrm{rad},{ }^{* *}: \mathrm{Nm} / \mathrm{rad} / \mathrm{s}\right)$

$$
\begin{gathered}
m_{b h} \ddot{x}_{b}=2 k_{p 4}\left(x_{p}-x_{b}\right)+2 c_{p 4}\left(\dot{x}_{p}-\dot{x}_{b}\right)+\left(-c_{p 2} \dot{\theta}_{h}-k_{p 2} \theta_{h}\right) / r_{4} \\
m_{b h} \ddot{y}_{b}=2 k_{p 5}\left(y_{p}-y_{b}\right)+2 c_{p 5}\left(\dot{y}_{p}-\dot{y}_{b}\right)-\left(-c_{p 6} \dot{\phi}_{h}-k_{p 6} \phi_{h}\right) / r_{5} \\
m_{b} \ddot{z}_{b}=k_{p 3}\left(z_{p}-z_{b}\right)+c_{p 3}\left(\dot{z}_{p}-\dot{z}_{b}\right)-\left[k_{p 1}\left(z_{b}-z_{h}\right)+c_{p 1}\left(\dot{z}_{b}-\dot{z}_{h}\right)\right] \\
+\left(-c_{p 2} \dot{\theta}_{h}-k_{p 2} \theta_{h}\right) / r_{3} \\
m_{h} \ddot{z}_{h}=k_{p 1}\left(z_{b}-z_{h}\right)+c_{p 1}\left(\dot{z}_{b}-\dot{z}_{h}\right)-\left(-c_{p 2} \dot{\theta}_{h}-k_{p 2} \theta_{h}\right) / r_{3}
\end{gathered}
$$




$$
\begin{aligned}
I_{h r} \ddot{\phi}_{h}= & -c_{p 6} \dot{\phi}_{h}-k_{p 6} \phi_{h} \\
& +m_{h b h} r_{1}\left[2 k_{p 5}\left(y_{p}-y_{b}\right)+2 c_{p 5}\left(\dot{y}_{p}-\dot{y}_{b}\right)-\left(-c_{p 6} \dot{\phi}_{h}-k_{p 6} \phi_{h}\right) / r_{5}\right] \\
I_{h p} \ddot{\theta}_{h}= & -c_{p 2} \dot{\theta}_{h}-k_{p 2} \theta_{h}+\left[k_{p 1}\left(z_{b}-z_{h}\right)+c_{p 1}\left(\dot{z}_{b}-\dot{z}_{h}\right)\right] r_{3} \\
& -m_{h b h} r_{2}\left[2 k_{p 4}\left(x_{p}-x_{b}\right)+2 c_{p 4}\left(\dot{x}_{p}-\dot{x}_{b}\right)+\left(-c_{p 2} \dot{\theta}_{h}-k_{p 2} \theta_{h}\right) / r_{4}\right]
\end{aligned}
$$

Where,

$$
m_{b h}=m_{b}+m_{h}, \quad m_{h b h}=\frac{m_{b}}{m_{b}+m_{h}} .
$$

Each parameter of the passenger model is set to $m_{b}=45 \mathrm{~kg}, m_{h}=7.5 \mathrm{~kg}, I_{h r}=8.3 \times 10^{-2} \mathrm{kgm}^{2}$, $I_{h p}=5.0 \mathrm{kgm}^{2}$, and $I_{h p}=5.5 \times 10^{-2} \mathrm{kgm}^{2}$ based on the adult male's height and weight data. In addition, the acceleration of the passenger's head is derived from a geometric relation.

$$
\begin{aligned}
& \ddot{x}_{h}=\ddot{x}_{b}+\ddot{\theta}_{h} / r_{2} \\
& \ddot{y}_{h}=\ddot{y}_{b}+\ddot{\phi}_{h} / r_{1}
\end{aligned}
$$

As shown in Table 2, the spring, the damper, and length were adjusted to conform the passenger model and an experimental data which was reported in previous research shown in Figs. 3 and 4 (Tamaoki et al., 1996, 1998). The results shown in Figs. 3(c) and 4(c) demonstrate that the gain characteristics of the model were nearly equal to the experimental ones. However, as shown in Figs. 3(b) and 4(b), there were some differences in the high-frequency band for the phase properties. To reduce these differences, the passenger model must be made more complex, but this necessitates the use of a higher order control system. Because the purpose of our controller is to reduce the vertical vibration of the passengers in comparison with the lateral vibration, we designed it using this passenger model.

\subsection{Vehicle-passenger model}

In this section, the passenger for the vehicle model was assumed to sit in the front-left seat in designing the control system to reduce passenger vibration and motion. The vehiclepassenger model is shown in Fig. 5. The passenger model is set to the vehicle model in a front-left seat to design the controller. The translational motion of the position of the seat and the motion of the vehicle have the following relation;

$$
\begin{aligned}
& x_{p 1}=\left(H_{p}+p_{1 z}\right) \theta \\
& y_{p 1}=-\left(H_{r}+p_{1 z}\right) \phi \\
& z_{p 1}=z_{c g}+p_{1 y} \phi-p_{1 x} \theta
\end{aligned}
$$

The equation of state of the vehicle-passenger model is defined as the following equation.

$$
\dot{x}(t)=A_{p} x(t)+B_{p 1} w(t)+B_{p 2} u(t)
$$



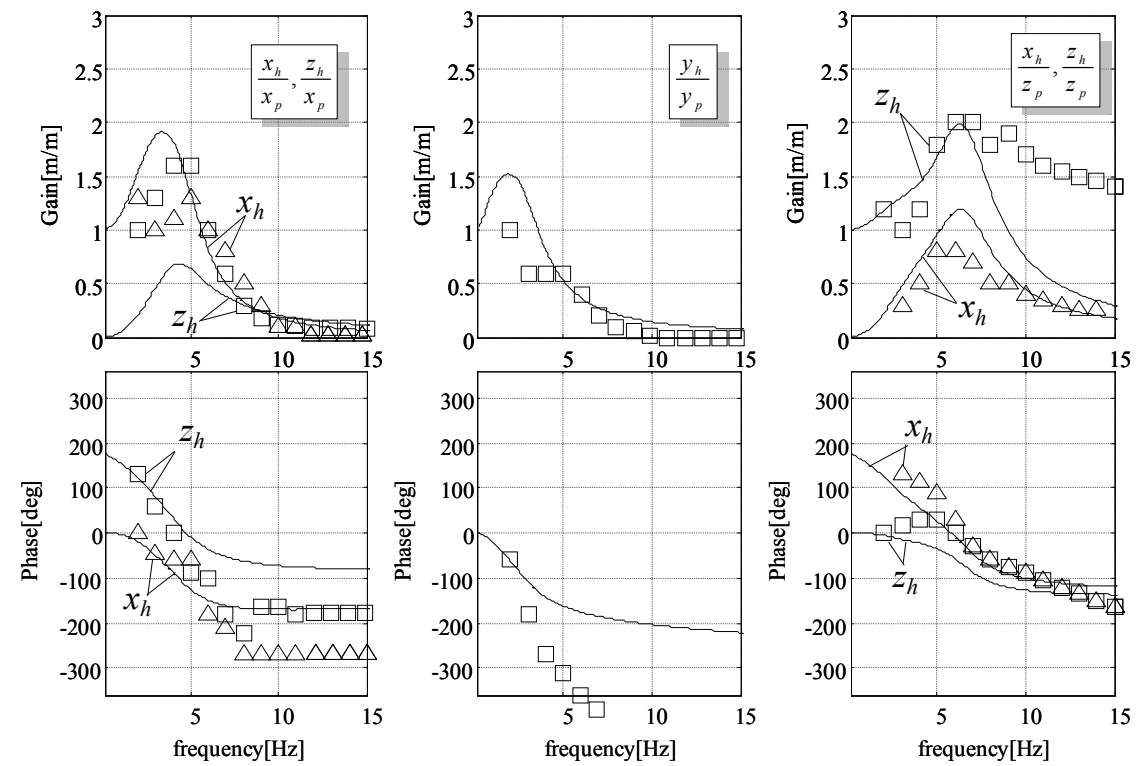

(a) $x_{p}$ input

(b) $y_{p}$ input

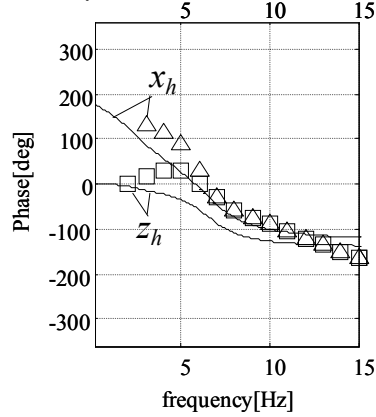

(c) $z_{p}$ input

Fig. 3. Transfer function from seat to the head (Translational motion, Dot: Experiment (Tamaoki et al., 1998), Line: model)
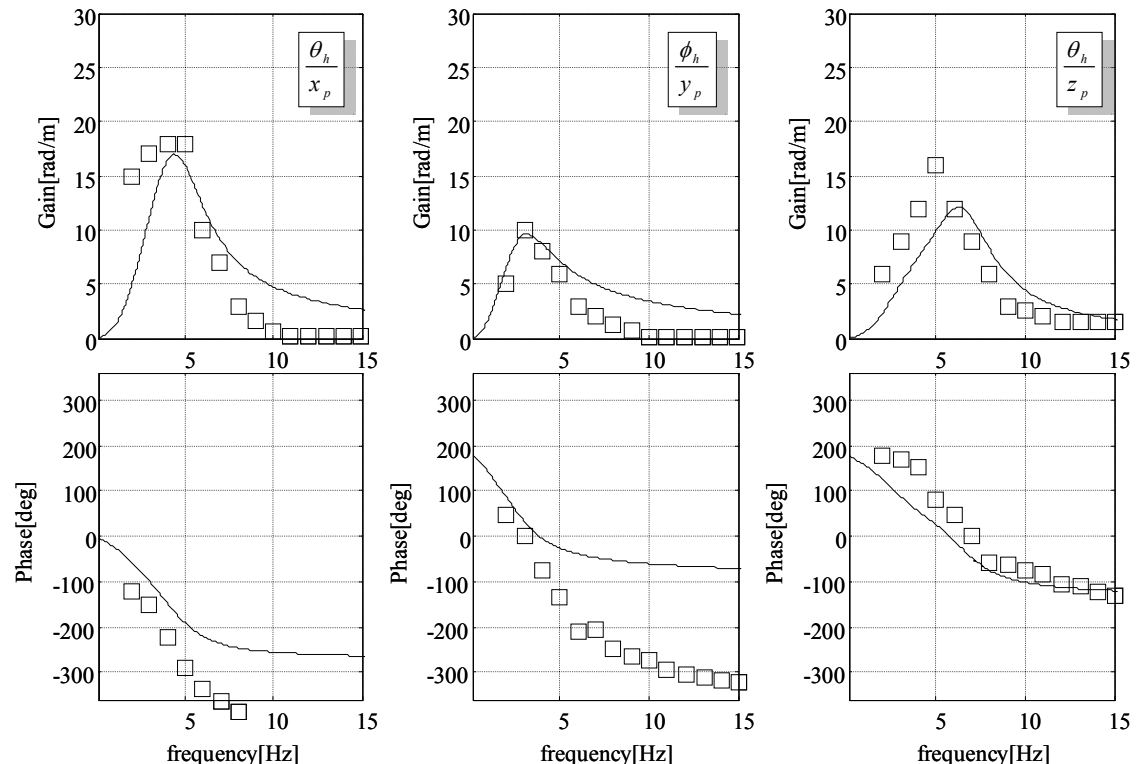

(a) $x_{p}$ input

(b) $y_{p}$ input

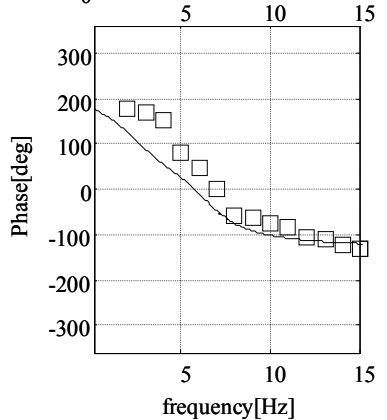

(c) $z_{p}$ input

Fig. 4. Transfer function from seat to the head (Rotational motion, Dot: Experiment (Tamaoki et al., 1996), Line: Model) 


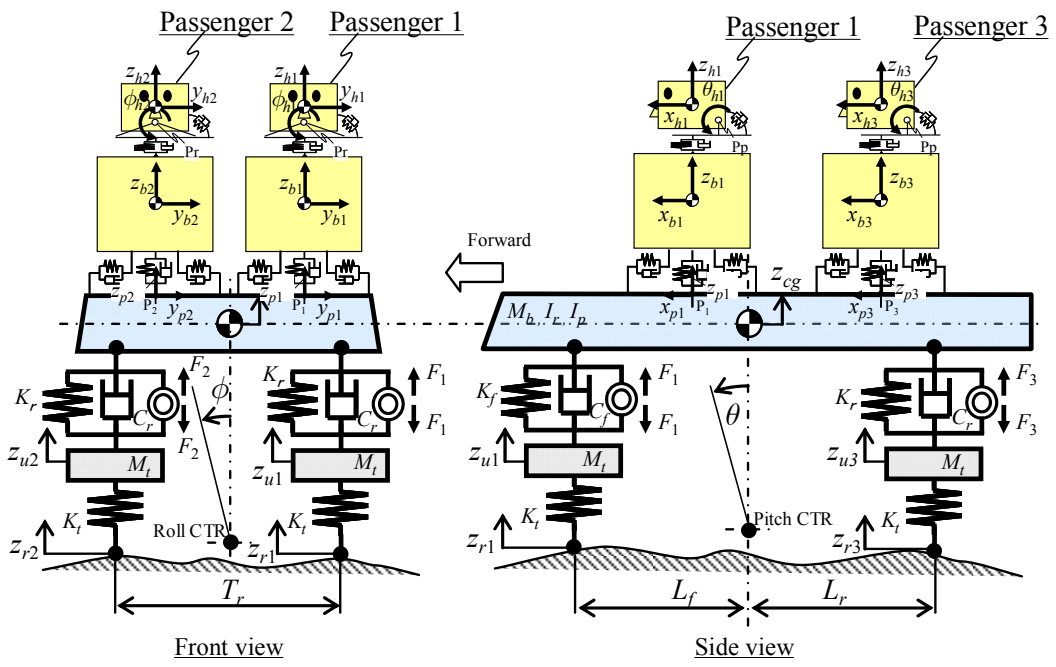

Fig. 5. Vehicle-passenger model

Where,

$$
\begin{aligned}
& x(t)=\left[z_{u 1} z_{u 2} z_{u 3} z_{u 4} z_{c g} \phi \theta \dot{z}_{u 1} \dot{z}_{u 2} \dot{z}_{u 3} \dot{z}_{u 4} \dot{z}_{c g} \dot{\phi} \dot{\theta} x_{b 1} y_{b 1} z_{b 1} z_{h} \phi_{h 1} \theta_{h 1} \dot{x}_{b 1} \dot{y}_{b 1} \dot{z}_{b 1} \dot{z}_{h} \dot{\phi}_{h 1} \dot{\theta}_{h 1}\right]^{T} \\
& w(t)=\left[z_{r 1} z_{r 2} z_{r 3} z_{r 4}\right]^{T} \\
& u(t)=\left[F_{1} F_{2} F_{3} F_{4}\right]^{T}
\end{aligned}
$$

\section{Design of controller}

\subsection{Disturbance accommodating control}

We found that feedforward control of disturbance information in the finite frequency range and feedback control improve performance (Okamoto et al., 2000). The power spectral density of the actual velocity of disturbances had flat characteristics in a low frequency, and decreased according to frequency at a region of high frequency. We assumed that it regarded as the colored noise formed by shaping filter which has a transfer function with low-pass characteristics. This filter of the each wheel is based on the road condition which defined by ISO (ISO-8608, 1995). The filter is as follows:

$$
\begin{aligned}
& Q_{d i}\left\{\begin{array}{l}
\dot{x}_{d i}(t)=A_{d i} x_{d i}(t)+B_{d i} w_{g i}(t) \\
w_{i}(t)=C_{d i} x_{d i}(t) \quad(i=1, \cdots, 4)
\end{array} .\right. \\
& \frac{w_{i}(s)}{w_{g i}(s)}=\frac{\varpi_{d}^{2}}{s^{2}+2 \xi_{d} \varpi_{d} s+\varpi_{d}^{2}} \quad(i=1, \cdots, 4)
\end{aligned}
$$

where, $w_{g i}$ is road input of the each wheel, $w_{i}$ is road input of the vehicle-passenger model of the generalized plant to design the controller as shown in Fig. 6. It was referred to as $\varpi_{d}=50 \times 2 \pi$ and $\xi_{d}=0.706$. 


\subsection{Disturbance accommodating $\boldsymbol{H}_{\infty}$ control.}

The feedforward control of disturbances resulted in worse accuracy outside the assumed frequency (Okamoto et al., 2000). Furthermore, because each resonance frequency of the vehicles, passenger, and tire differs, the control system design considering each resonance frequency is needed. Therefore, the control system was designed by using the $H_{\infty}$ method in the control theory.

We integrated each state variable of the road disturbance model and frequency weights for controlled values. The frequency weights are as follows:

$$
\begin{aligned}
& Q_{w i}\left\{\begin{array}{l}
\dot{x}_{w i}(t)=A_{w i} x_{w i}(t)+B_{w i} z_{p i}(t) \\
z_{g i}(t)=C_{w i} x_{w i}(t) \quad(i=1, \cdots, 4)
\end{array} .\right. \\
& \frac{z_{g i}(s)}{z_{p i}(s)}=K_{w i} W_{i}(s) \quad(i=1, \cdots, 4)
\end{aligned}
$$

where, $z_{p i}$ is controlled value of the vehicle-passenger model, $z_{g i}$ is controlled value of the generalized plant. Figure 6 shows a block diagram of the generalized plant to design the controller, and the state-space form of the generalized plant is as follows:

$$
\begin{aligned}
& \dot{x}_{g}(t)=A_{g} x_{g}(t)+B_{g 1} w_{g}(t)+B_{g 2} u(t) \\
& z_{g}(t)=C_{g 1} x_{g}(t) \quad+D_{g 12} u(t) . \\
& y_{g}(t)=C_{g 2} x_{g}(t)+D_{g 21} w_{g}(t)
\end{aligned}
$$

$H_{\infty}$ norm of the transfer function from disturbance $w_{g}(t)$ to controlled value $z(t)$ is expressed by the following equation.

$$
\begin{gathered}
\left\|G_{z_{g} w_{g}}\right\|_{\infty}=\sup _{w} \frac{\left\|z_{g}\right\|_{2}}{\left\|w_{g}\right\|_{2}} \\
\min _{u} \| G_{z_{g} w_{g} \|_{\infty}}=: \gamma^{*}
\end{gathered}
$$

where, $\gamma^{*}$ is a minimum of $H_{\infty}$ norm of the generalized plant realized with $H_{\infty}$ controller. The controller is the following equation (Glover \& Doyle, 1988).

$$
\begin{aligned}
& \dot{x}_{k}(t)=A_{k} x_{k}(t)+B_{k} y(t) \\
& u(t)=C_{k} x_{k}(t)
\end{aligned}
$$

The measured outputs, $y(t)$, are four vertical accelerations of the wheel position of the vehicle body. The controlled values, $z(t)$, are vertical acceleration of the passenger's head, vertical velocity of the sprung, tire deformation, and actuating force. Frequency weight $W_{i}$, shown in Fig. 7 was determined by trial and error.

A bandpass filter, $W_{1}$, that had a peak frequency equal to the resonance frequency of the passenger's head was used based on sensitivity curves (ISO-2631-1, 1997), such as that being standardized by ISO and shown in Fig. 8. In order to prevent the increase of response in each resonance, a low pass filter $W_{2}$ and a bandpass filter $W_{3}$ are used. Moreover, to prevent steady control input and minimize energy consumption, a high pass filter, $W_{4}$, was used. 
We compare the proposal method and two generalized control methods to verify the control performance. As one of the generalized control methods, the controller in which the one of the controlled values is vertical acceleration of the body CoG (Vehicle CoG Control), is designed. Another is that one of the controlled values is vertical acceleration of a seated position (Seat Position Control). The design of two generalized control methods are changed the controlled value $z_{1}$ into the vertical acceleration of CoG of the vehicle body and seated position, respectively. Frequency weights, $W_{1}(s), W_{2}(s), W_{3}(s), W_{4}(s), K_{w 2}=400, K_{w 3}=5000$, and $K_{w 4}=1.31$, use the same value also in the three methods. The following section describes $K_{w 1}$.

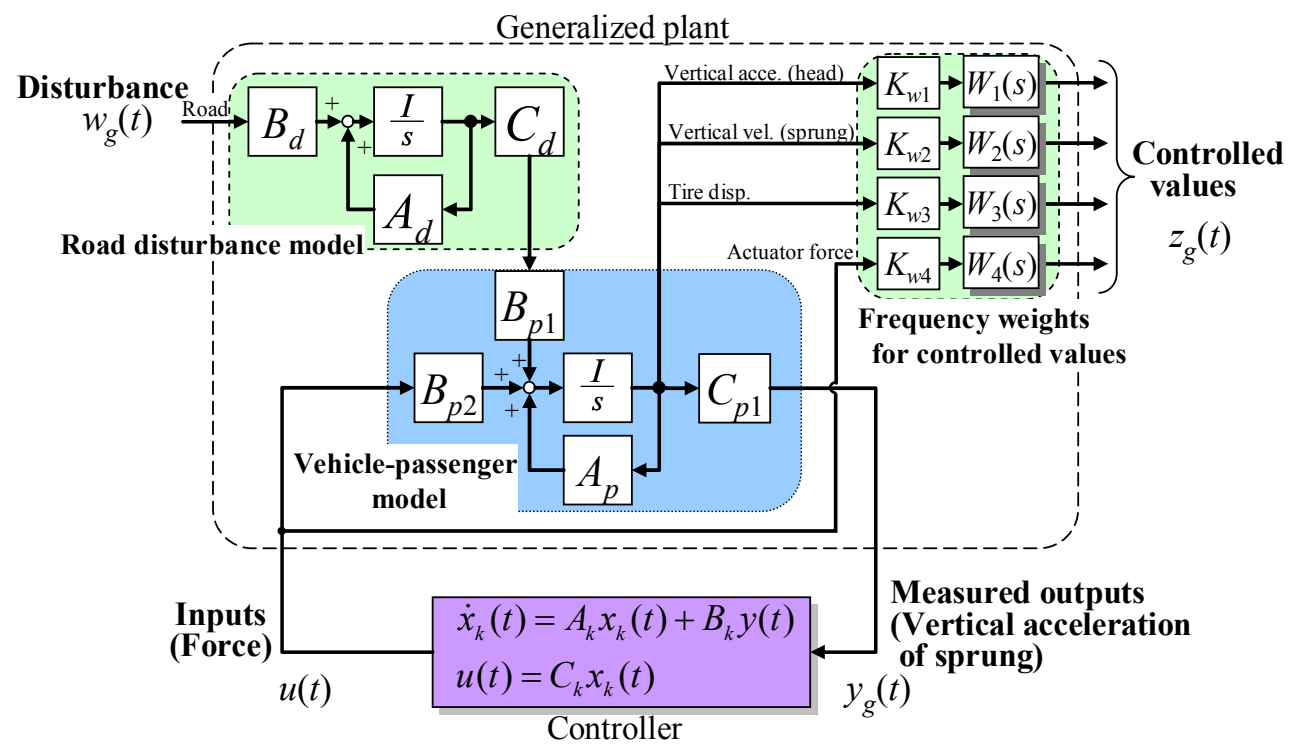

Fig. 6. Generalized plant for "Passenger Control"

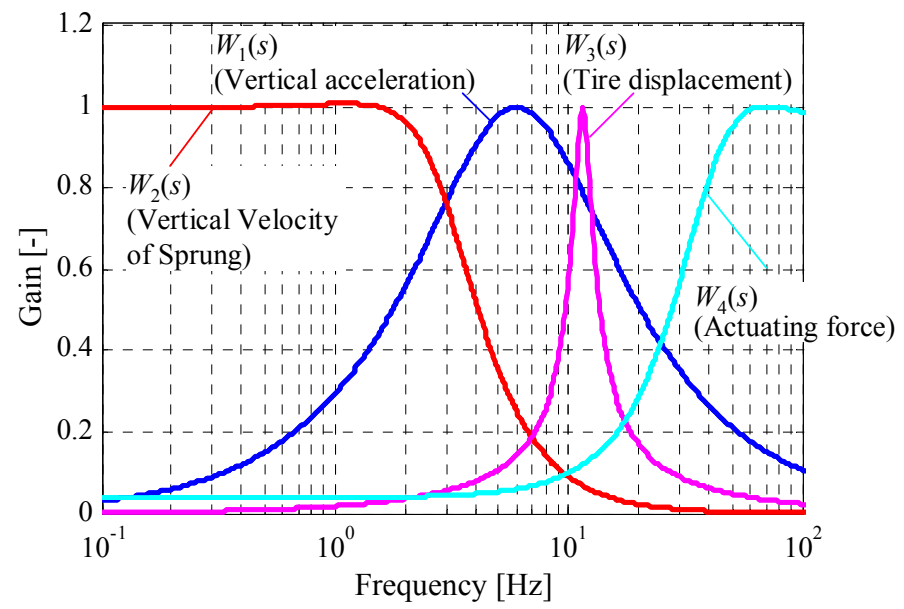

Fig. 7. Frequency weights for controlled value 


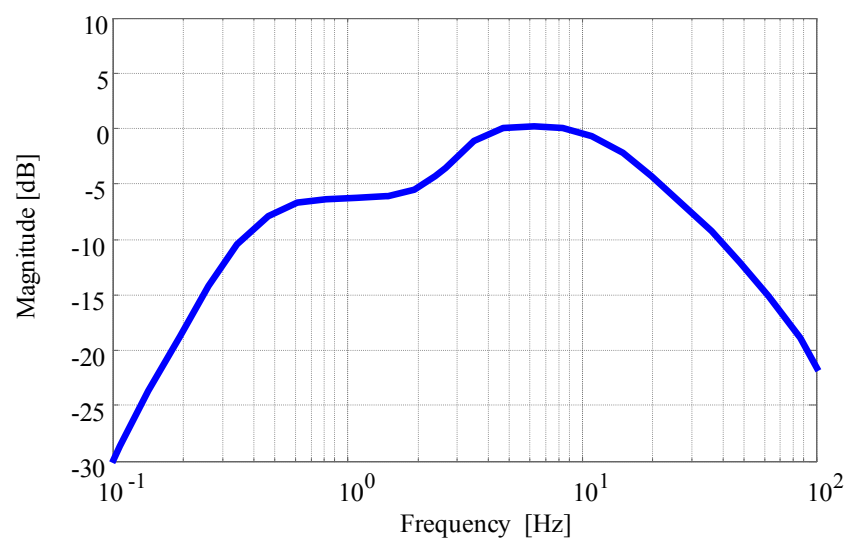

Fig. 8. Sensitivity curve of vertical vibration (ISO-2631-1, 1997)

\section{Simulation}

In this section, two kinds of numerical simulations were carried out. One is to verify control performance in comparison with other methods. Another is to verify robustness for the difference in passenger's vibration characteristic.

\subsection{Assumption}

We verified the effectiveness of the proposed method by using the vehicle-passenger model with $H_{\infty}$ controller. We used MATLAB (The Math Work Inc.) for the calculations, and the Runge-Kutta method for the differential equations. The computational step size is $1 \mathrm{~ms}$. In addition, it assumes that we perform the evaluation in an ideal condition, and the model to design the controller and the model for evaluation are same models.

\subsection{Driving condition}

It assumes that the PSD characteristic of the road surface is C class defined by ISO (ISO$8608,1995)$. The vehicle speed is $16.6 \mathrm{~m} / \mathrm{s}(60 \mathrm{~km} / \mathrm{h})$. The vehicle runs the straight for 10 seconds, and the input of the road surface to each wheel is independent. Figure 9 shows the PSD of the road disturbance. Figure 10 shows the road displacement.

\subsection{Design of the frequency weight $K_{w 1}$}

In each method, if the evaluation function of acceleration is raised, it is clear that each acceleration set as the controlled value is reduced, and the actuating force increases. To set the same actuating force, frequency weight $K_{w 1}$ of each method was adjusted so that RMS value of the actuating force of the four wheels sets to $1000 \mathrm{~N}$. The each frequency weight, $K_{w 1}$, of "Vehicle CoG Control", "Seat Position Control" and "Passenger Control" is 244, 315, and 78 respectively.

\subsection{Difference of vehicle-passenger model}

In the numerical simulation, there are some diffidence in the vehicle-passenger model as shown in Table 3. In sections 4.5.1 and 4.5.2, passenger models sit in the front-left seat and 
front-right seat. In section 4.5.2, some specifications of the passenger model are different from the generalized plant to design controller.

\subsection{Results}

\subsubsection{Comparison with the "Vehicle CoG Control" and "Seat Position Control"}

Figure 11 shows the time histories of the vehicle and the passenger 1's vertical acceleration for 3 second. In this paper, passenger 1 sits a front-left seat, and passenger 2 sits a frontright. In the acceleration of the vehicle body, it was confirmed that there is few differences among the three methods. On the other hand, in the acceleration of the passenger's head, the proposed method is the smallest, and it was confirmed that the proposed method is effective for the passenger's vibration reduction.

The actuating force of each wheel in each method is shown in Fig. 12. In the Vehicle CoG Control, the actuating force of all wheels is generated in the same direction. In the other method, the actuating force of the left/right wheel is generated in a different direction. Therefore, the vertical accelerations of the seated position and the passenger's head are reduced by controlling the roll motion of the vehicle body.

Figure 13 shows the Lissajous figure of lateral and vertical accelerations of the seated position, the passenger's body and the head part respectively. This figure is seen from the front of vehicle. In upper-right figure of Fig. 13 (c), the proposed method has control effect which vertical acceleration of the passenger 1's head is reduced in comparison with "Vehicle CoG Control". Moreover, the proposed method has not only the vibration reduction effect of the passenger 1's head, but also the vertical acceleration reduction effect of the passenger 1 's body.

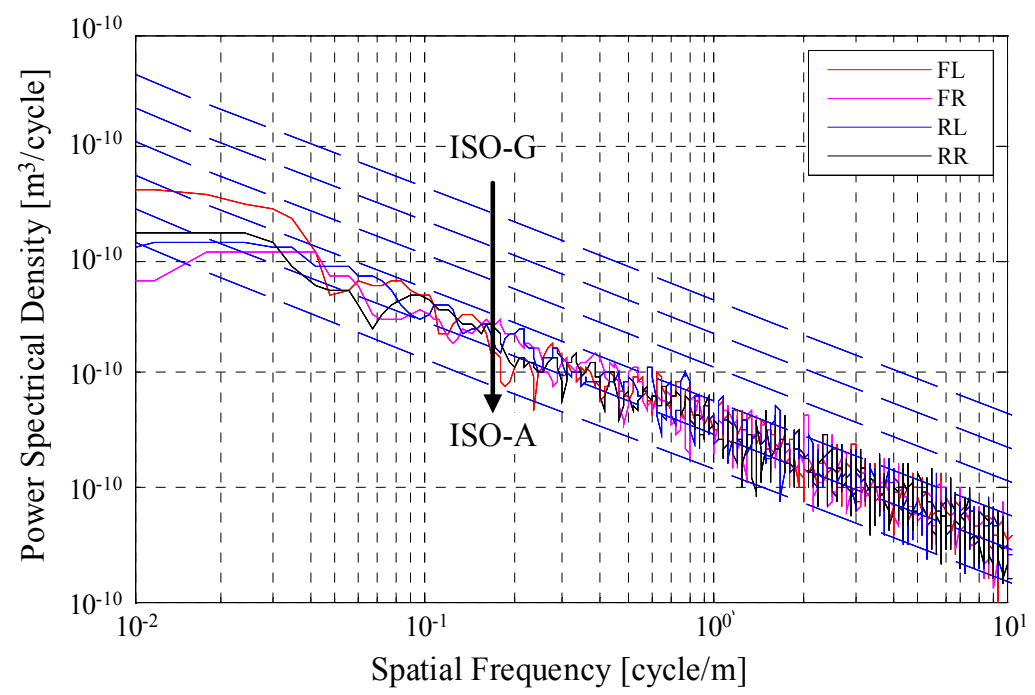

Fig. 9. PSD of road surface profile 
Figure 14 shows power spectrum density (PSD) of the vertical acceleration of the passenger's head in each method, and actuating force. In the frequency band of 4-7 Hz with resonance of a passenger's head, although the proposed method has the vibration reduction effect better than other methods. On the other hand, PSD of the actuating force does not necessarily have the highest value in the frequency band. In this frequency band, the proposed method can reduce the passenger's vibration by the limited actuating force.

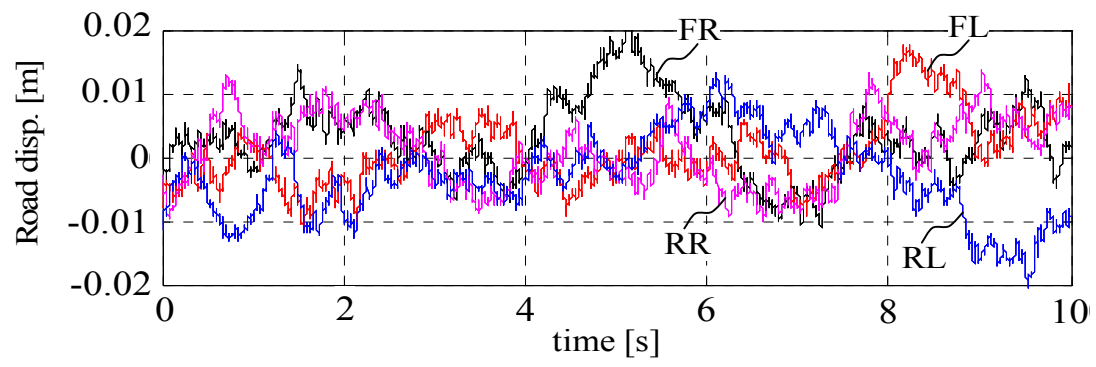

Fig. 10. Road displacement

\begin{tabular}{|c|c|c|c|}
\hline \multirow{2}{*}{} & \multirow{2}{*}{$\begin{array}{c}\text { Generalized plant } \\
\text { to design controller }\end{array}$} & \multicolumn{2}{|c|}{ Simulation model } \\
\cline { 3 - 4 } & Fig. 1, Table 1 & $\leftarrow$ & $\leftarrow$ \\
\hline \hline Vehicle & Fig. 2, Table 2 & $\leftarrow$ & Table 4 \\
\hline Passenger & $\bullet$ Front-left & $\begin{array}{c}\text { •Front-left } \\
\text {.Front-right }\end{array}$ & $\leftarrow$ \\
\hline Seated position & & & \\
\hline
\end{tabular}

Table 3. Vehicle-passenger model

In each frequency band, the sensitivity of the vertical acceleration for the human is defined by sensitivity curves (ISO-2631, 1997). In this paper, we estimate the root mean square (RMS) value which is added the sensitivity compensation expressed by a high order transfer function (Rimel \& Mansfield, 2007). Figure 15 shows the ratio of the RMS value of each vertical acceleration to those values of "Vehicle CoG Control". In the passenger 1, it was confirmed that the proposed method can reduce the RMS value of the passenger 1's head (head 1). Moreover, in the passenger 2, it was confirmed that the RMS value of the passenger 2's head (head 2) is not increased by the proposed method, and the proposed method had the vibration reduction effect equivalent to the generalized control methods. 


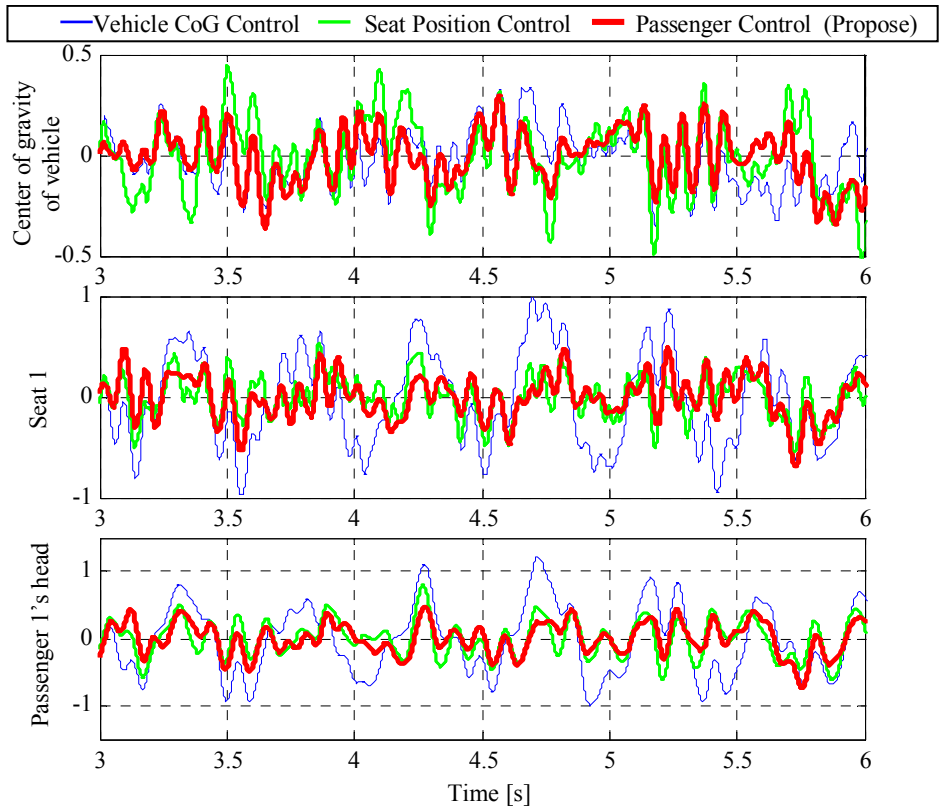

Fig. 11. Vehicle and passenger's behavior (Vertical acceleration, unit : $\mathrm{m} / \mathrm{s}^{2}$ )

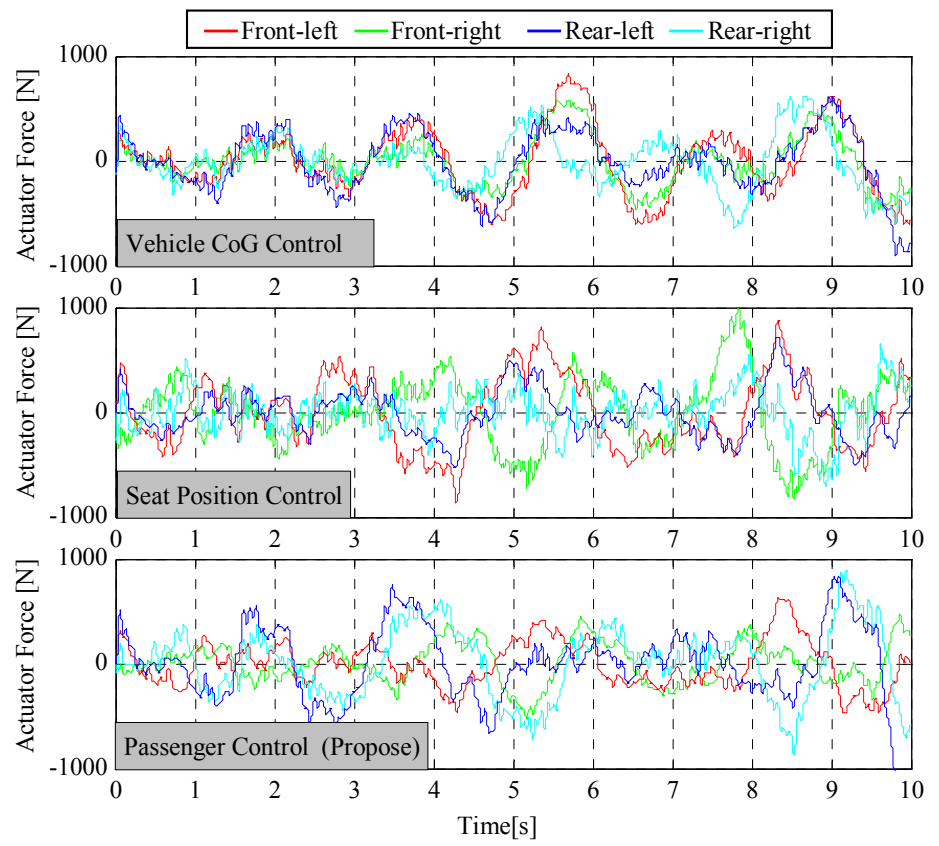

Fig. 12. Actuating force 

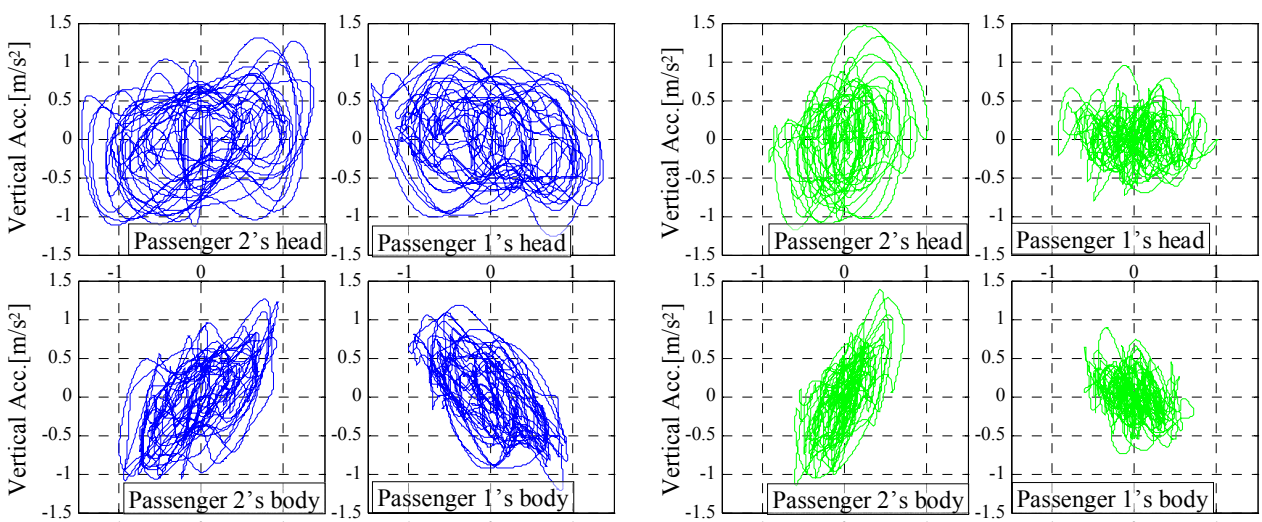

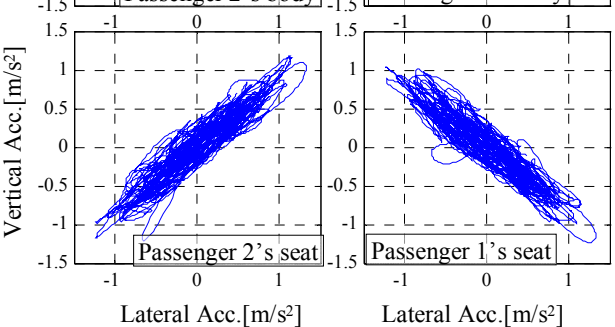

(a) Vehicle CoG Control

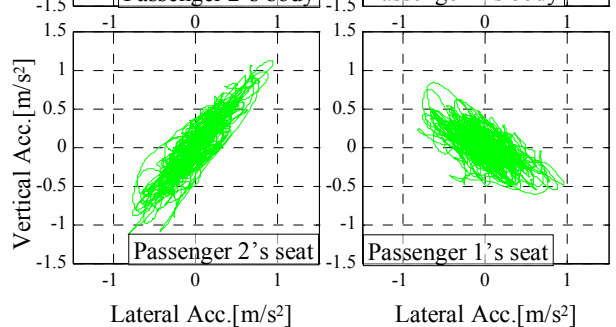

(b) Seat Position Control
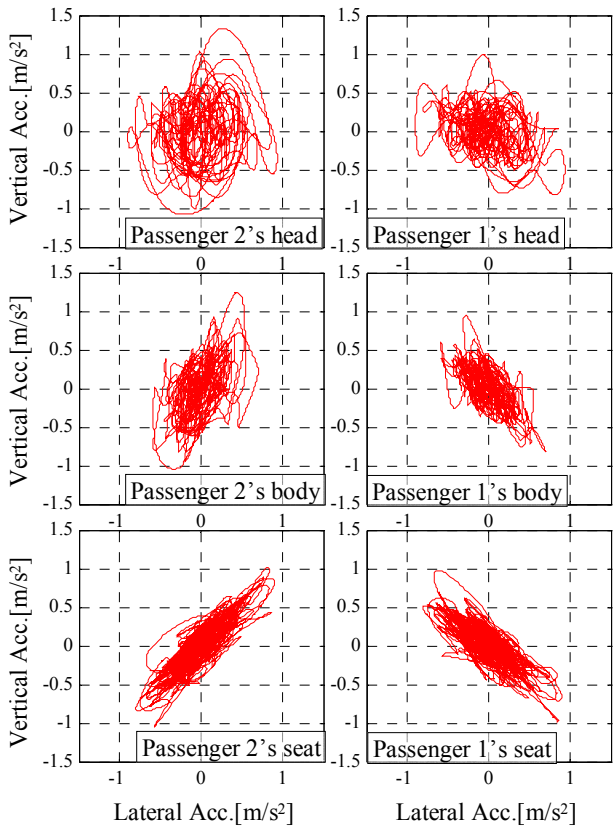

(c) Passenger Control (Propose)

Fig. 13. Lissajous figure (Lateral and vertical acceleration) 
$\longrightarrow$ Vehicle CoG Control - Seat Position Control $-\quad$ Passenger Control (Propose)

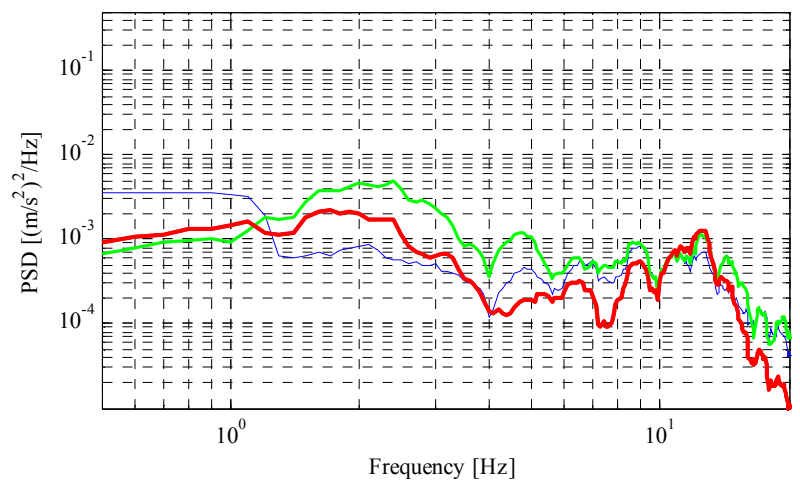

(a) Vertical acceleration (Center of gravity of vehicle)

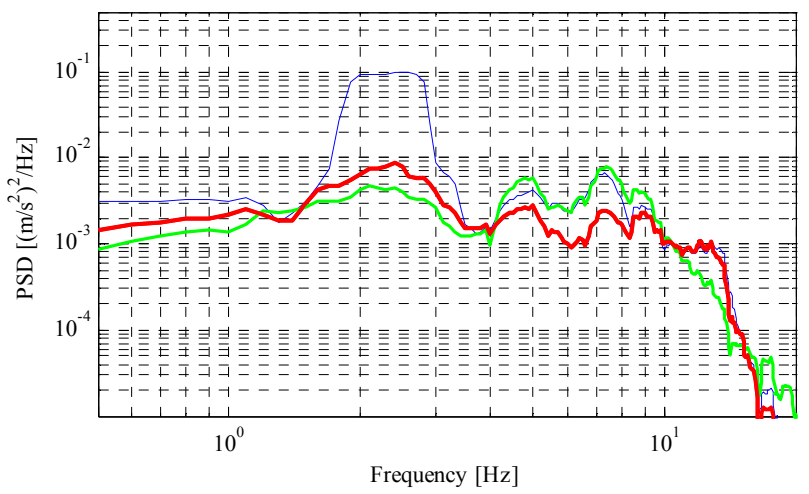

(b) Vertical acceleration (Passenger1's head)

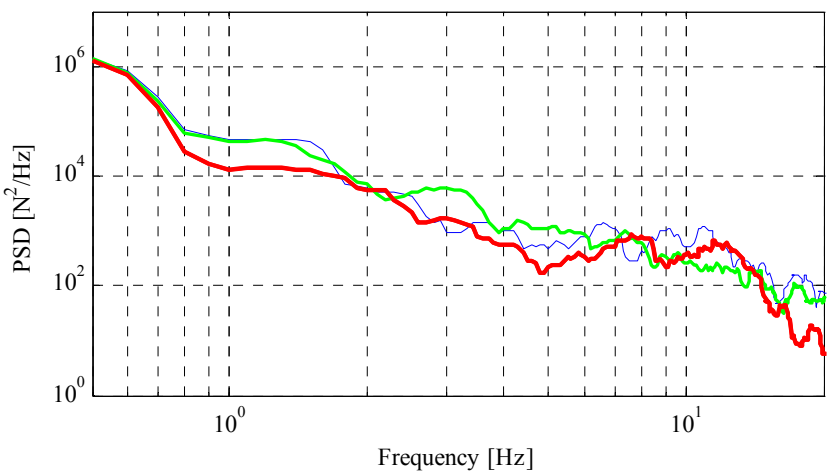

(c) Actuator force

Fig. 14. Power spectral density 


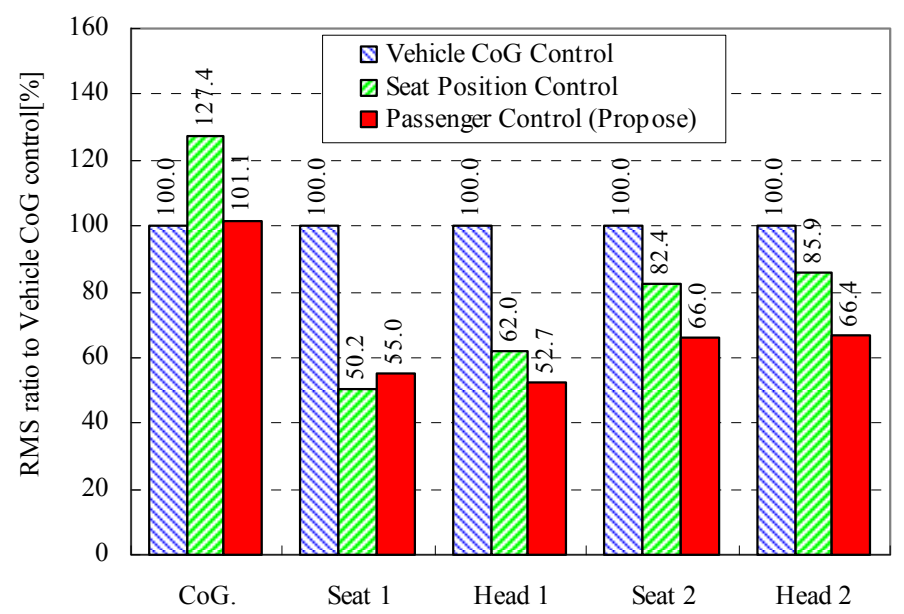

Fig. 15. RMS value of vertical acceleration

From these results, it was confirmed that the proposed method can effectively reduce passenger's vibration by using $H_{\infty}$ control which including the dynamics of human body and seated position. By means of setting the passenger' motion to one of the amounts of evaluation function, the proposed method can directly control the passenger's vibration.

\subsubsection{Comparison with the different passenger model}

In this section, the robust performance against the difference in a passenger's vibration characteristic is verified. In previous research, there are many reports about seated human

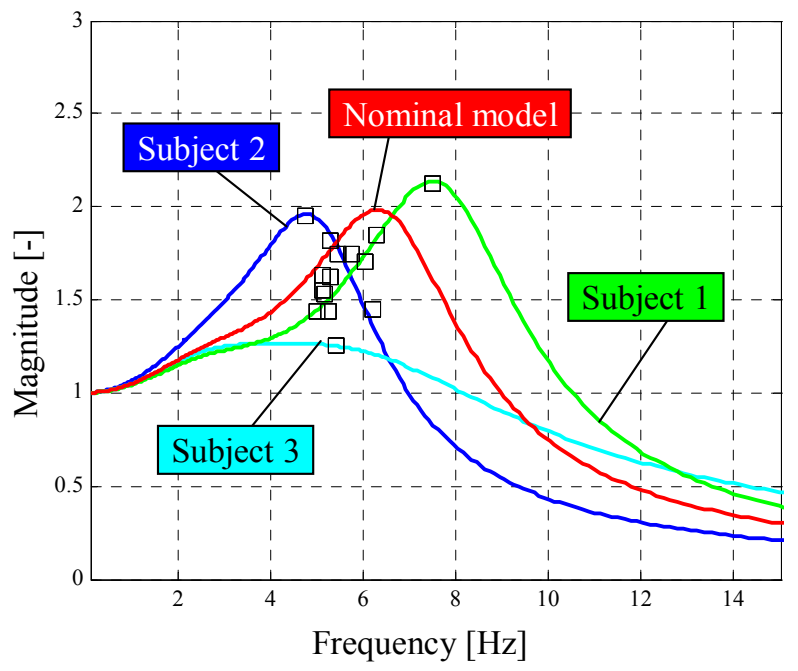

Fig. 16. Frequency response from seat to the head (Vertical motion, dot : Experiment (Varterasian \& Thompson, 1977), Line : Model) 
dynamics. Varterasian \& Thompson reported the seated human dynamics from a large person to a small person(Varterasian \& Thompson, 1977). Robust performance is verified by supposition that such person sits in the vehicle. Figure 16 shows the frequency response from vertical vibration of seat to vertical vibration of the head. Dot is 15 subjects' resonance peak. In this section, three outstanding subjects' data of their report is modeled in the vibration characteristic of vertical direction. The damper and spring were adjusted to conform the passenger model and an experimental data. The characteristic of the passenger model of three outstanding subjects are shown in Table 4.

\begin{tabular}{|c|c|c|}
\hline & $\begin{array}{c}k_{p 3} \\
{[\mathrm{~N} / \mathrm{m}]}\end{array}$ & $\begin{array}{c}c_{p 3} \\
{[\mathrm{~N} / \mathrm{m} / \mathrm{s}]}\end{array}$ \\
\hline \hline Nominal model & 960000 & 1120 \\
\hline Subject 1 & 1320000 & 1150 \\
\hline Subject 2 & 576000 & 960 \\
\hline Subject 3 & 960000 & 2550 \\
\hline
\end{tabular}

Table 4. Difference of specifications

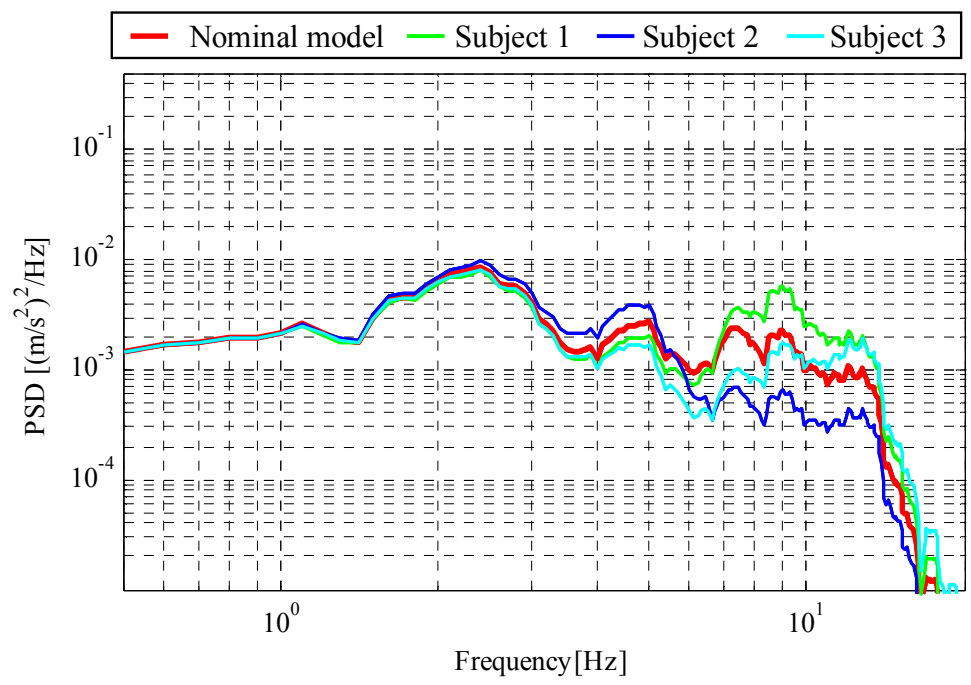

Fig. 17. PSD of vertical acceleration (Passenger 1's head)

The numerical simulation is carried out on the same road surface conditions as the section 4.5.1. Figure 17 shows PSD of the vertical acceleration of the passenger 1's head and Fig. 18 
shows RMS value. In PSD of $7 \mathrm{~Hz}$ or more, RMS value of vertical acceleration of subject 1's head becomes higher than the nominal model. Moreover, RMS of subject 1 is the highest. On the other hand, RMS of subjects 2 and 3 is reduced in comparison with the nominal model. The physique of subject 1 differs from other subjects. When such a person sits, the specified controller should be designed. From these results, the proposed method has robustness for the passenger of the general physique.

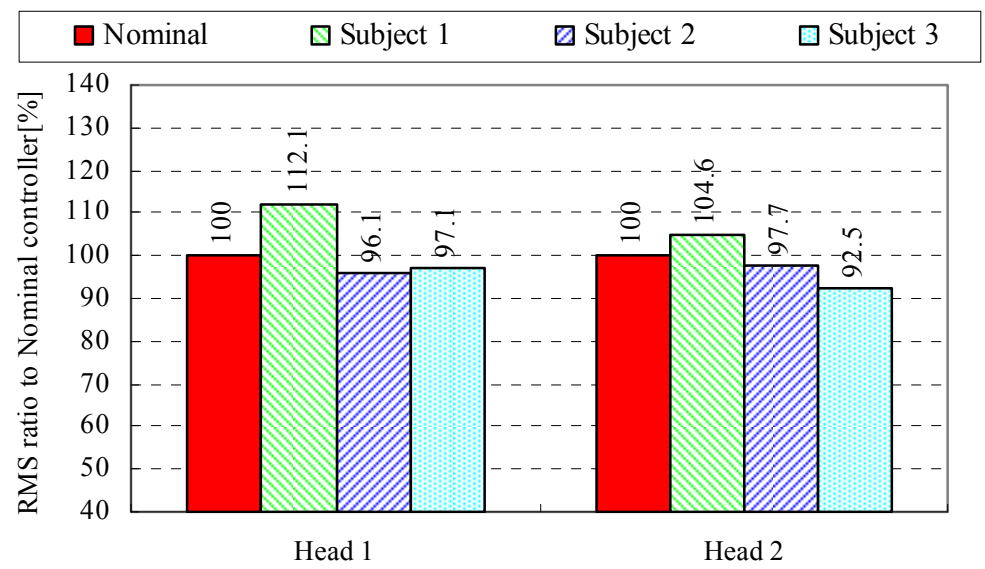

Fig. 18. RMS value of vertical acceleration of passenger 1's head

\section{Conclusion}

This study aims at establishing a control design method for the active suspension system in order to reduce the passenger's vibration. In the proposed method, a generalized plant that uses the vertical acceleration of the passenger's head as one of the controlled output is constructed to design the linear $H_{\infty}$ controller. In the simulation results, when the actuating force is limited, we confirmed that the proposed method can reduce the passenger's vibration better than two methods which are not include passenger's dynamics. Moreover, the proposed method has robustness for the difference in passenger's vibration characteristic.

\section{Acknowledgment}

This work was supported in part by Grant in Aid for the Global Center of Excellence Program for "Center for Education and Research of Symbiotic, Safe and Secure System Design" from the Ministry of Education, Culture, Sport, and Technology in Japan.

\section{References}

Ikeda, S.; Murata, M.; Oosako, S. \& Tomida, K. (1999). Developing of New Damping Force Control System -Virtual Roll Damper Control and Non-liner $H_{\infty}$ Control-, Transactions of the TOYOTA Technical Review, Vol.49. No.2, pp.88-93 
Kosemura, R.; Takahashi, M. \& and Yoshida, K. (2008). Control Design for Vehicle SemiActive Suspension Considering Driving Condition, Proceedings of the Dynamics and Design Conference 2008, 547, Kanagawa, Japan, September, 2008

Itagaki, N.; Fukao, T.; Amano, M.; Ichimaru, N.; Kobayashi, T. \& Gankai, T. (2008). SemiActive Suspension Systems based on Nonlinear Control, Proceedings of the 9th International Symposium on Advanced Vehicle Control 2008, pp. 684-689, Kobe, Japan, October, 2008

Tamaoki, G.; Yoshimura, T. \& Tanimoto, Y. (1996). Dynamics and Modeling of Human Body Considering Rotation of the Head, Proceedings of the Dynamics and Design Conference 1996, 361, pp. 522-525, Fukuoka, Japan, August, 1996

Tamaoki, G.; Yoshimura, T. \& Suzuki, K. (1998). Dynamics and Modeling of Human Body Exposed to Multidirectional Excitation (Dynamic Characteristics of Human Body Determined by Triaxial Vibration Test), Transactions of the Japan Society of Mechanical Engineers, Series C, Vol.64, No.617, pp. 266-272

Tamaoki, G. \& Yoshimura, T. (2002). Effect of Seat on Human Vibrational Characteristics, Proceedings of the Dynamics and Design Conference 2002, 220, Kanazawa, Japan, October, 2002

Koizumi, T.; Tujiuchi, N.; Kohama, A. \& Kaneda, T. (2000). A study on the evaluation of ride comfort due to human dynamic characteristics, Proceedings of the Dynamics and Design Conference 2000, 703, Hiroshima, Japan, October, 2000 ISO-2631-1 (1997). Mechanical vibration and shock-Evaluation of human exposure to whole-body vibration -, International Organization for Standardization ISO-5982 (2001). Mechanical vibration and shock -Range of idealized value to characterize seated body biodynamic response under vertical vibration, International Organization for Standardization

Oya, M.; Tsuchida, Y. \& Qiang, W. (2008). Robust Control Scheme to Design Active Suspension Achieving the Best Ride Comfort at Any Specified Location on Vehicles, Proceedings of the 9th International Symposium on Advanced Vehicle Control 2008, pp.690-695, Kobe, Japan, October, 2008

Guglielmino, E.; Sireteanu, T.; Stammers, C. G.; Ghita, G. \& Giuclea, M. (2008). Semi-Active Suspension Control -Improved Vehicle Ride and Road Friendliness, Springer-Verlag, ISBN- 978-1848002302, London

Okamoto, B. and Yoshida, K. (2000). Bilinear Disturbance-Accommodating Optimal Control of Semi-Active Suspension for Automobiles, Transactions of the Japan Society of Mechanical Engineers, Series C, Vol.66, No.650, pp. 3297-3304

Glover, K. \& Doyle, J.C. (1988). State-space Formula for All Stabilizing Controllers that Satisfy an $H_{\infty}$-norm Bound and Relations to Risk Sensitivity, Journal of the Systems and Control letters, 11, pp.167-172

ISO-8608 (1995). Mechanical vibration -Road surface profiles - Reporting of measured data, International Organization for Standardization

Rimel, A.N. \& Mansfield, N.J. (2007). Design of digital filters for Frequency Weightings Required for Risk Assessment of workers Exposed to Vibration, Transactions of the Industrial Health, Vol.45, No.4, pp. 512-519 
Varterasian, H. H. \& Thompson, R. R. (1977). The Dynamic Characterristics of Automobiles Seats with Human Occupants, SAE Paper, No. 770249 


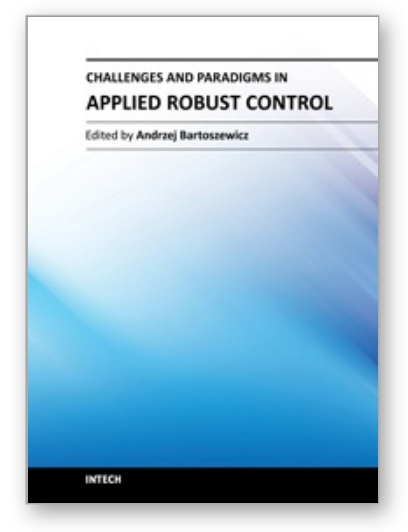

\author{
Challenges and Paradigms in Applied Robust Control \\ Edited by Prof. Andrzej Bartoszewicz
}

ISBN 978-953-307-338-5

Hard cover, 460 pages

Publisher InTech

Published online 16, November, 2011

Published in print edition November, 2011

The main objective of this book is to present important challenges and paradigms in the field of applied robust control design and implementation. Book contains a broad range of well worked out, recent application studies which include but are not limited to $\mathrm{H}$-infinity, sliding mode, robust PID and fault tolerant based control systems. The contributions enrich the current state of the art, and encourage new applications of robust control techniques in various engineering and non-engineering systems.

\title{
How to reference
}

In order to correctly reference this scholarly work, feel free to copy and paste the following:

Takuma Suzuki and Masaki Takahashi (2011). Robust Active Suspension Control for Vibration Reduction of Passenger's Body, Challenges and Paradigms in Applied Robust Control, Prof. Andrzej Bartoszewicz (Ed.), ISBN: 978-953-307-338-5, InTech, Available from: http://www.intechopen.com/books/challenges-andparadigms-in-applied-robust-control/robust-active-suspension-control-for-vibration-reduction-of-passenger-sbody

\section{INTECH}

open science | open minds

\section{InTech Europe}

University Campus STeP Ri

Slavka Krautzeka 83/A

51000 Rijeka, Croatia

Phone: +385 (51) 770447

Fax: +385 (51) 686166

www.intechopen.com

\section{InTech China}

Unit 405, Office Block, Hotel Equatorial Shanghai

No.65, Yan An Road (West), Shanghai, 200040, China

中国上海市延安西路65号上海国际贵都大饭店办公楼 405 单元

Phone: +86-21-62489820

Fax: +86-21-62489821 
(C) 2011 The Author(s). Licensee IntechOpen. This is an open access article distributed under the terms of the Creative Commons Attribution 3.0 License, which permits unrestricted use, distribution, and reproduction in any medium, provided the original work is properly cited. 